\title{
Analytical Methods for the Determination of Anti-Psoriatic Drugs - A Review
}

\section{Sistla Mounica Pratyusha* and Choppala Asha Deepti}

Department of Pharmaceutical Analysis and Quality Assurance, GITAM Institute of Pharmacy, GITAM (Deemed to be) University, Visakhapatnam, Andhra Pradesh, India

*Corresponding Author: Sistla Mounica Pratyusha, Department of Pharmaceutical Analysis and Quality Assurance, GITAM Institute of Pharmacy, GITAM (Deemed to be) University, Visakhapatnam, Andhra Pradesh, India.

DOI: $10.31080 /$ ASPS.2020.04.0490
Received: January 20, 2020

Published: January 31, 2020

(C) All rights are reserved by Sistla Mounica

Pratyusha and Choppala Asha Deepti.

\begin{abstract}
Psoriasis is a long-lasting autoimmune disease characterized by patches of abnormal skin. Typical psoriatic scales are in thick, red patches. Sometimes, these patches will crack and bleed. Psoriasis is the result of a sped-up skin production process. Some of the drugs used in the treatment of psoriasis are Acitretin, Etretinate, Bergapten, Methoxsalen, Tazarotene, Calcipotriol, Anthralin etc. A brief review of the analytical methods developed for the determination of drugs used for the treatment of Psoriasis was discussed in the present study.

Keywords: Acitretin; Etretinate; Bergapten
\end{abstract}

\section{Introduction}

Psoriasis is a chronic autoimmune condition that causes the rapid build-up of skin cells. This build-up of cells causes scaling on the skin's surface. Typically, skin cells grow deep in the skin and slowly rise to the surface. The typical life cycle of a skin cell is one month. Some of the drugs used in the treatment of psoriasis: Acitretin, Etretinate, Bergapten, Methoxsalen, Tazarotene, Calcipotriol, Anthralin and the chemical structures of these drugs were given in figure 1 . The analytical methods so developed for the determination of these drugs were summarized in table 1.

Acitretin $\left(\mathrm{C}_{21} \mathrm{H}_{26} \mathrm{O}_{3}\right)$ is an oral retinoid used in the treatment of severe resistant psoriasis and is generally used in only very severe cases of psoriasis that have been unresponsive to other treatments $[1,2]$. Acitretin is available with brand names ACERET, ACETEC, ACITRIN, ACROTAC. Analytical methods such as HPLC [3-5], HPTLC [6], LC-ESI-MS/MS [7] were developed for the determination of Acitretin (Table 1).

Etretinate $\left(\mathrm{C}_{23} \mathrm{H}_{30} \mathrm{O}_{3}\right)$ is a medication used to treat severe psoriasis. It is a synthetic aromatic retinoid. The mechanism of action of Etretinate is still not understood but the action may be due to the interference with the terminal differentiation of keratinocytes [8]. Etretinate is available with brand names TEGISON (10 mg), TEGI-

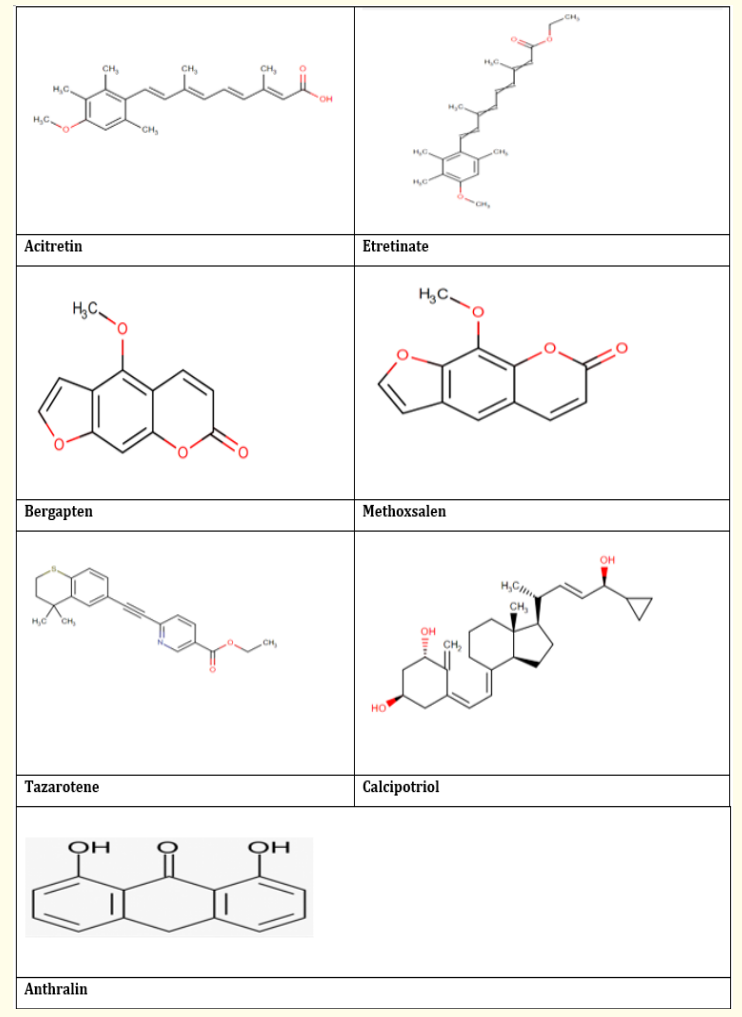

Figure 1: Chemical structures of Anti-psoriatic drugs. 


\begin{tabular}{|c|c|c|}
\hline Method & Mobile phase (v/v) / Reagent & Ref \\
\hline \multicolumn{3}{|l|}{ Acitretin } \\
\hline HPLC & Glacial acetic acid: Acetonitrile: Iso propyl alcohol (0.3: 70:30) & [3] \\
\hline HPLC & Ethanol: Water: Glacial acetic acid (7: 2.97: 0.03) & {$[4]$} \\
\hline HPLC & Acetic acid buffer: Methanol: THF (12:85:3) & [5] \\
\hline HPTLC & Acetonitrile: Chloroform (1:9) & [6] \\
\hline LC-ESI-MS/MS & $20 \mathrm{mM}$ Ammonium acetate buffer: Acetonitrile (5:95) & [7] \\
\hline \multicolumn{3}{|l|}{ Etretinate } \\
\hline HPLC & $\begin{array}{l}\text { Mobile phase A: } 10 \% \text { Ammonium acetate: Water: Acetonitrile: Acetic acid (8: 72: 20: } 0.8 \text { ). } \\
\qquad \text { Mobile phase B: consists of two components } \\
\text { (i) } 10 \% \text { Ammonium acetate: Water: Acetonitrile: Acetic acid (0.4: 29.6: 70: } 0.3 \text { ) } \\
\text { (ii) } 10 \% \text { Ammonium acetate: Water: Acetonitrile: Acetic acid (0.4: 14.6: 85: } 0.1)\end{array}$ & {$[9]$} \\
\hline \multicolumn{3}{|l|}{ Bergapten } \\
\hline LC-MS/MS & Methanol: Water (75:25) & [11] \\
\hline \multicolumn{3}{|l|}{ Methoxsalen } \\
\hline HPLC & Methanol: Acetonitrile: Water $(2: 30: 68)$ & [13] \\
\hline HPLC & Acetonitrile: 0.01 M Phosphoric acid (34:66) & [14] \\
\hline LC/MS and NMR & Methanol: 6\% THF (aqueous) & [15] \\
\hline \multicolumn{3}{|l|}{ Tazarotene } \\
\hline HPTLC & Toluene: Methanol (9: 1). & [17] \\
\hline UV & Benzene: Chloroform: Ammonia (5: 5: 0.01) & [18] \\
\hline HPLC & $\begin{array}{c}\text { Mobile phase A: Buffer: Organic modifier }(40: 60) \\
\text { Mobile phase B: Organic modifier } \\
\text { Buffer: } 10 \mathrm{mM} \mathrm{KH}_{2} \mathrm{PO}_{4} \text { with pH } 3.0 \text { by ortho phosphoric acid } \\
\text { Organic modifier: Methanol: THF (95:5) }\end{array}$ & [19] \\
\hline \multicolumn{3}{|l|}{ Calcipotriol } \\
\hline HPLC & Methanol: Water $(80: 20)$ & [21] \\
\hline \multicolumn{3}{|l|}{ Anthralin } \\
\hline HPLC & Acetonitrile: Methanol: Buffer (20:20:60) & [23] \\
\hline HPLC & Acetonitrile: Water: Acetic acid (58:37:5) & [24] \\
\hline
\end{tabular}

Table 1: Review of analytical methods published for the drugs used in psoriasis.

SON (25 mg) and only one analytical method i.e. HPLC [9] was developed for the determination of Etretinate along with other compounds in plasma (Table 1). Bergapten $\left(\mathrm{C}_{12} \mathrm{H}_{8} \mathrm{O}_{4}\right)$ is used to treat more pigmentary diseases involving sun exposure [10] and LC-MS/ MS [11] were developed for the estimation of Bergapten (Table 1).

Methoxsalen $\left(\mathrm{C}_{12} \mathrm{H}_{8} \mathrm{O}_{4}\right)$ is a drug used to treat psoriasis, eczema, vitiligo, and some cutaneous lymphomas. Methoxsalen modifies the way of skin cells to receive the radiation for treating the disease [12]. Methoxsalen is available as Maxlen, Meladerm, Octamop, Vitilen. Analytical methods such as HPLC $[13,14]$, LC/MS and NMR [15] were developed for the estimation of Methoxsalen (Table 1).
Tazarotene $\left(\mathrm{C}_{21} \mathrm{H}_{21} \mathrm{NO}_{2} \mathrm{~S}\right)$ is a third generation prescription topical retinoid sold as a cream, gel, or foam. Tazarotene belongs to acetylenic class of retinoids. It is available in two concentrations: $0.1 \%$ and $0.05 \%$ [16]. Tazarotene is most commonly used topically to treat acne, psoriasis and to reduce skin wrinkling and liver spots. Tazarotene is available as TAZORAC, ZORAC, AVAGE, and FABIOR. Analytical methods such as HPTLC [17], UV [18], RP-HPLC [19] were developed for the estimation of Tazarotene (Table 1).

Calcipotriol or Calcipotriene, is a derivative of vitamin D used in the treatment of psoriasis and safe for long-term application. [20]. 
Calcipotriol, is available as DAIVONEX, PSOTRIOL. HPLC [21] was developed for the estimation of Calcipotriol (Table 1).

Dithranol is a hydroxyl anthrone applied to the skin of patients with psoriasis. It is available as cream, ointment or paste in 0.1 to 2\% strengths with brand names DRITHOCREME, DITHROCREA, MICANOL, PSORLIN, DRITHO-SCALP, ANTHRAFORTE, ANTHRANOL and ANTHRASCALP. Dithranol has a slow onset of action in controlling psoriasis, typically several weeks, compared to glucocorticoid steroids but is without the potential for rebound reaction on withdrawal [22]. Analytical methods such as HPLC [23,24] were developed for the estimation of Anthralin (Table 1).

\section{Conclusion}

The present review is very much helpful for the authors working in the field of analytical chemistry for method development and validation of drugs used in the treatment of psoriasis.

\section{Bibliography}

1. Parisi R., et al. "Global epidemiology of psoriasis: a systematic review of incidence and prevalence". Journal of Investigative Dermatology 133.2 (2013): 377-385.

2. Orfanos CE., et al. "Current use and future potential role of retinoids in dermatology". Drugs 53.3 (1997): 358-388.

3. Porwal PK., et al. "Assessment by HPLC of the degradation behavior of Acitretin under hydrolytic, oxidative, photolytic and thermal stress conditions". Acta Pharmaceutica Sinica B 4.6 (2014): 438-446.

4. Porwal PK., et al. "Stability-indicating RP-HPLC method validation for Acitretin and its related substances in capsules". Journal of Pharmaceutical Research 9.3 (2010): 122-125.

5. Devika Subramaniyan G., et al. "Determination of Acitretin in pharmaceutical formulations by HPLC method". International Journal of Pharmaceutics and Drug Analysis 4.3 (2016): 147152.

6. Srikanth Inturi., et al. "India Estimation of Acitretine in softule dosage form by HPTLC method". Journal of Pharmacy Research 5.5 (2012): 2926-2929.

7. Kumar A., et al. "Stability-indicating validation of Acitretin and isoacitretin in human plasma by LC-ESI-MS/MS bioanalytical method and its application to pharmacokinetic analysis". Biomedical Chromatography 25.6 (2011): 680-688.
8. Saurat JH., et al. "Retinoids and psoriasis: Novel issues in retinoid pharmacology and implications for psoriasis treatment". Journal of the American Academy of Dermatology 41.3 (1999): S2-6.

9. Wyss R., et al. "Quantitative analysis of retinoids in biological fluids by high-performance liquid chromatography using column switching. II. Simultaneous determination of Etretinate, Acitretin and 13-cis-Acitretin in plasma". Journal of Chromatography 431.2 (1988): 297-307.

10. Honigsmann., et al. "5-Methoxypsoralen (Bergapten) in photo chemotherapy of psoriasis". British Journal of Dermatology 101 (1979) 369-378.

11. Gao Y., et al. "Pharmacokinetic studies of Bergapten in dog plasma by using a LC-MS/MS method studies". Drug Research 63.7 (2013): 338-341.

12. Von Weymarn LB., et al. "Effects of 8-methoxypsoralen on cytochrome P450 2A13". Carcinogenesis 26.3 (2005): 621-629.

13. Monbaliu JG., et al. "Analysis of Methoxsalen in plasma by reversed-phase high-performance liquid chromatography". Journal of Pharmaceutical Sciences 70.8 (1981): 965-966.

14. Kucová D., et al." High-performance liquid chromatographic determination of Methoxsalen in plasma after liquid-solid extraction". Journal of chromatography 614.2 (1993): 340-344.

15. Lehr GJ., et al. "LC determination of impurities in Methoxsalen drug substance: isolation and identification of isopimpinellin as a major impurity by atmospheric pressure chemical ionization LC/MS and NMR". Journal of Pharmaceutical and Biomedical Research 33.4 (2003): 627-637.

16. Attar M., et al. "Cytochrome P450 2C8 and flavin-containing monooxygenases are involved in the metabolism of Tazarotenic acid in humans". 31.4 (2003): 476-481.

17. Mrunali R., et al. "HPTLC method for estimation of Tazarotene in topical gel formulations and in vitro study". Analytical methods 3 (2010).

18. Eman S., et al "A novel simple method for resolving overlapped spectral data with a wide range of applicability, and its application as a stability indicating method for determination of Tazarotene". Pharmaceutica Analytica Acta 3.10 (2012): 21532435. 
19. Chinmoy Roy., et al "Stability indicating RP-HPLC method development and validation for determination of process related impurities and degradation products of Tazarotene in Tazarotene topical formulation". Indo American Journal of Pharmaceutical Research 3.1 (2012): 1400-1413.

20. Kim DH., et al. "Successful treatment of alopecia areata with topical Calcipotriol”. Annals of Dermatology 24.3 (2012): 341344.

21. Madhulika Pradhan., et al "Development and Validation of a Robust RP-HPLC Method for Analysis of Calcipotriol in Pharmaceutical Dosage Form". Research Journal of Pharmacy and Technology 12.2 (2019): 579-583.

22. Ashton RE, et al. "Anthralin: historical and current perspectives". Journal of the American Academy of Dermatology 9.2 (1983): 173-192.

23. Sunil prakash C., et al. "Development of RP-HPLC method for estimation of Dithranol in hydrogel based lipid nanoparticle formulation". Current Trends in Technology and Sciences 1.2 (2012): 104-107.

24. Suja George., et al "A Simple RP-HPLC method for the determination of the anti-psoriatic drug Dithranol and its application in an in vitro cell uptake study". Current Pharmaceutical Analysis 8.1 (2012): 75-82.

\section{Assets from publication with us}

- Prompt Acknowledgement after receiving the article

- Thorough Double blinded peer review

- Rapid Publication

- Issue of Publication Certificate

- High visibility of your Published work

Website: https://www.actascientific.com/

Submit Article: https://www.actascientific.com/submission.php Email us: editor@actascientific.com

Contact us: +919182824667 